\title{
The Application of Labview-based Virtual Instrument Technology In Nondestructive Testing
}

\author{
Li Wang $^{1, \text { a }}$, Zhaohua Wang ${ }^{2}$ \\ ${ }^{1}$ Department of Energy Engineering, Yulin University, Yulin 719000, Shannxi, China \\ a278116312@qq.com
}

Keywords: virtual instrument; LabVIEW; nondestructive testing

Abstract. With the rapid development of science and technology in China today, nondestructive testing (NDT) has also made dramatic progress. The intelligence of testing process and foolproof of operation process is the most immediate embodiment of this progress, while most of the time such progress needs to be supported by LabVIEW and other software platforms virtual instrument. For this end, in this article, the author conducts a specific study on the application of LABVIEW-based virtual instrument technology in NDT, in the hope that this study could bring inspiration to relevant practitioners.

\section{Introduction}

NDT refers to testing in all ways without damaging or affecting the performance of the tested object. It largely reflects the industrial level of a country. In the economic and scientific progress of China, NDT plays a vital role. To give a better play to this role is why the author conducts a specific study on the application of LABVIEW-based virtual instrument technology in NDT in this paper.

\section{Overview of Virtual Instrument}

Virtual instrument plays a decisive role in NDT discussed in this paper. With ever-increasing demands for NDT, the importance of virtual instrument has been elevated. The author found in an actual survey that the current NDT in China was showing a development trend towards intelligent testing process, foolproof operation process and complex measured signals. Driven by this trend, the performance superiority of instrument hardware is downplayed. Naturally the proportion of virtual instrument in NDT is strengthened [1].

As far as current professionals in China are concerned, the cognition of "software= instrument" is very popular among the industry. Under this cognition, the number of NDTs conducted on LabVIEW and other virtual instrument software platforms is rising. Tab. 1 compares advantages and disadvantages between virtual instrument and conventional instrument in NDTs. Combined with this table, we can understand the importance of virtual instrument for NDT more intuitively [2].

Tab. 1 Comparison between Virtual Instrument and Conventional Instrument

\begin{tabular}{cc}
\hline Virtual Instrument & Conventional Instrument \\
\hline $\begin{array}{c}\text { The features are defined by the user } \\
\text { The development and maintenance costs } \\
\text { are low }\end{array}$ & $\begin{array}{c}\text { The functions are defined by the } \\
\text { instrument manufacturer and are fixed } \\
\text { The development and maintenance costs } \\
\text { are high }\end{array}$ \\
The system is open & $\begin{array}{c}\text { The system is closed. The connection has } \\
\text { limitations }\end{array}$ \\
$\begin{array}{c}\text { Technologies update quickly } \\
\text { User-friendly and } \\
\text { web-based }\end{array}$ & Technologies update slowly \\
\end{tabular}




\section{LabVIEW and Virtual Instrument}

To ensure that virtual instrument better meets the needs of NDT, large-scale manufacturers and scientific research institutions at home and abroad have developed software platform systems related to virtual instrument vigorously in recent years. LabVIEW discussed in this paper is just one of the representatives. Different from conventional sequential programming language, LabVIEW platform belongs to compiling graphical programming language. The distinction of this programming language is mainly embodied in graphical development and debugging of LabVIEW platform system. The graphical programming of LabVIEW platform system is the most notable feature of LabVIEW platform system. Fig. 1 shows a schematic of LabVIEW platform system [3].

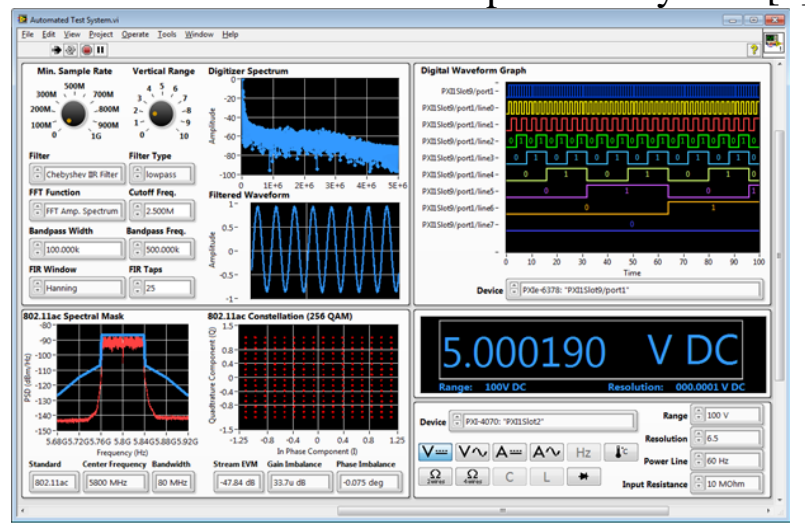

Fig. 1 Schematic of LabVIEW Platform System

The emergence of the feature of graphical programming of LabVIEW platform system allows LabVIEW platform system to be called as visual instrument. Three parts, front panel, block diagram and icon/interface are concrete composition of LabVIEW platform system. Tab. 2 displays this composition visually. From this table, we can understand the front panel, block diagram and icon/interface of LabVIEW platform system more intuitively.

Tab. 2 Composition of LabVIEW Platform System

\begin{tabular}{|c|c|}
\hline Composition & Specific Function \\
\hline Front panel & $\begin{array}{l}\text { The front panel of LabVIEW platform system plays a role of } \\
\text { human-computer interaction in LabVIEW platform system. This kind } \\
\text { of human-computer interaction is implemented by parameter setting } \\
\text { and output interface display. When a front panel is used, the LabVIEW } \\
\text { platform system user can "draw" on the panel by operation, without } \\
\text { the need of programming [4]. }\end{array}$ \\
\hline $\begin{array}{c}\text { Block } \\
\text { diagram }\end{array}$ & $\begin{array}{l}\text { The main function of the block diagram of LabVIEW platform system } \\
\text { is to define the data flow direction between entry and exit. This } \\
\text { function also makes the block diagram an executive program of } \\
\text { LabVIEW platform system. Supported by the block diagram, relevant } \\
\text { designers can select different function icons from function modules } \\
\text { and realize graphical programming by connection. Such kind of codes, } \\
\text { as if drawn, makes programs written by LabVIEW platform system } \\
\text { simple, artistic and visual. Besides, the block diagram also offers } \\
\text { powerful support to NDT. Fig. } 2 \text { shows a schematic of block diagram } \\
\text { of LabVIEW platform system [5]. }\end{array}$ \\
\hline $\begin{array}{c}\text { Icon/ } \\
\text { interface }\end{array}$ & $\begin{array}{c}\text { The icon/interface is also an important component of LabVIEW } \\
\text { platform system. This component is mainly responsible for displaying } \\
\text { the diagram of sub-virtual instrument in the block diagram of } \\
\text { upper-level virtual instrument. }\end{array}$ \\
\hline
\end{tabular}




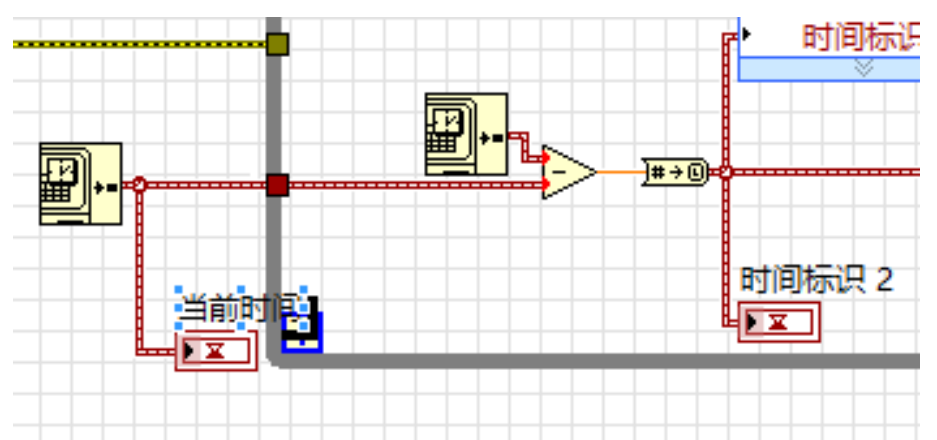

Fig. 2 Block Diagram of LabVIEW Platform System

Hardware interfaces and analysis features are characteristics of LabVIEW platform system. To understand these characteristics more intuitively, hardware interfaces and analysis features of LabVIEW platform system are displayed visually in Tab. 3.

Tab. 3 Display of Hardware Interfaces and Analysis Features

\begin{tabular}{|c|c|c|}
\hline System Characteristic & Connotation & Representative \\
\hline Hardware interface & \begin{tabular}{lr} 
Guarantee & \multicolumn{2}{r}{ normal } \\
operation of Windows \\
driver hardware in \\
LabVIEW \\
system;
\end{tabular} & $\begin{array}{l}\text { RS232/422, VXI } \\
\text { digital I/O board); }\end{array}$ \\
\hline Analysis feature & $\begin{array}{l}\text { Provide all kinds of } \\
\text { analysis features (a total of } \\
\text { 70) for LabVIEW platform } \\
\text { system }\end{array}$ & $\begin{array}{l}\text { Digital signal processing } \\
\text { and digital filter, etc., and } \\
\text { support codes written in C } \\
\text { language to make } \\
\text { LabVIEW platform system } \\
\text { better meet user demands. }\end{array}$ \\
\hline
\end{tabular}

\section{The Application of LabVIEW-Based Virtual Instrument in NDT}

From the above content, we can gain a deeper understanding of LabVIEW platform system. To ensure that the present study goes deeper, we also need to clarify the application of LABVIEW-based virtual instrument in NDT. Therefore, the author takes a practical case of NDT in China that applied LabVIEW and obtained certain results for example, with a view that this case could inspire relevant practitioners.

3.1 Crude oil pipeline leakage real-time monitoring and positioning system

In the application of LABVIEW-based virtual instrument in NDT, crude oil pipeline leakage real-time monitoring and positioning system is a representative of such kind of application. Such application solved security problems triggered by the status quo in China, such as the quality of crude oil pipelines and management growth. As a result, losses caused by related accidents were greatly reduced. In the concrete establishment of crude oil pipeline leakage monitoring and real-time positioning system, relevant designers adopted acoustic emission technology. Through the application of LabVIEW platform system, this system judged leakage by bus-based high-speed data acquisition and analysis. Tab. 4 shows results of leakage test of this crude oil pipeline leakage real-time monitoring and positioning system. From this table, we can understand the effectiveness of this crude oil pipeline leakage real-time monitoring and positioning system visually.

Tab. 4 Results of Leakage Test

\begin{tabular}{lllll}
\hline No. & Leak Point $(\mathrm{km})$ & Position $(\mathrm{km})$ & Absolute Error $(\mathrm{km})$ & Relative Error $(\%)$ \\
\hline 1 & 5.7 & 5.52 & -0.18 & 1.07 \\
2 & 13.5 & 13.61 & 0.11 & 0.65 \\
\hline
\end{tabular}

3.2 Acousto-ultrasonic composite material testing system

The acousto -ultrasonic composite material testing system is also an important application field of LabVIEW-based virtual instrument in NDT. This application is a new dynamic NDT technology 
coupled with LabVIEW. The proposed acousto -ultrasonic composite material testing system adopts ISA bus, PRC35 Pulser/Receiver Card, as well as DLL library interface and algorithm embedding functions of LabVIEW. This design allows the acousto-ultrasonic composite material testing system to meet the needs of various NDTs properly. The successful testing of honeycomb composite materials is the best proof of the practicality of this system.

\section{Conclusion}

In the present study on the application of LABVIEW-based virtual instrument technology in NDT, the author elaborates on concepts of virtual instrument, LabVIEW and virtual instrument and the application of LABVIEW-based virtual instrument in NDT, and so on. Combined with this series of content, we can be well aware of the significance of LabVIEW platform system for existing NDT in China. The open architecture and powerful analysis features, etc. also broaden the future application scope of this system. Hopefully relevant enterprises could attach great importance to this system.

\section{References}

[1] Cho H M, Cho H S, Kim K S, et al. Experimental study on the application of a compressed-sensing (CS)-based deblurring method in x-ray nondestructive testing and its image performance[J]. Ndt \& E International, 2015, 75:1-7.

[2] Belkacemi M, Stolz C, Mathieu A, et al. Nondestructive testing based on scanning-from-heating approach: application to nonthrough defect detection and fiber orientation assessment[J]. Journal of Electronic Imaging, 2015, 24(6):061112.

[3] Lu Z, Xu C, Xiao D, et al. Nondestructive Testing Method for Curved Surfaces Based on the Multi-Gaussian Beam Model[J]. Journal of Nondestructive Evaluation, 2015, 34(4):1-9.

[4] Denzler J K, Weidenhiller A. Pre-grading of spruce logs containing frozen and unfrozen water by means of frequency-based nondestructive testing (NDT)[J]. Holzforschung, 2015, 70(1):79-85.

[5] Kim Y Y, Kwon Y E. Review of magnetostrictive patch transducers and applications in ultrasonic nondestructive testing of waveguides.[J]. Ultrasonics, 2015, 62:3 - 19. 